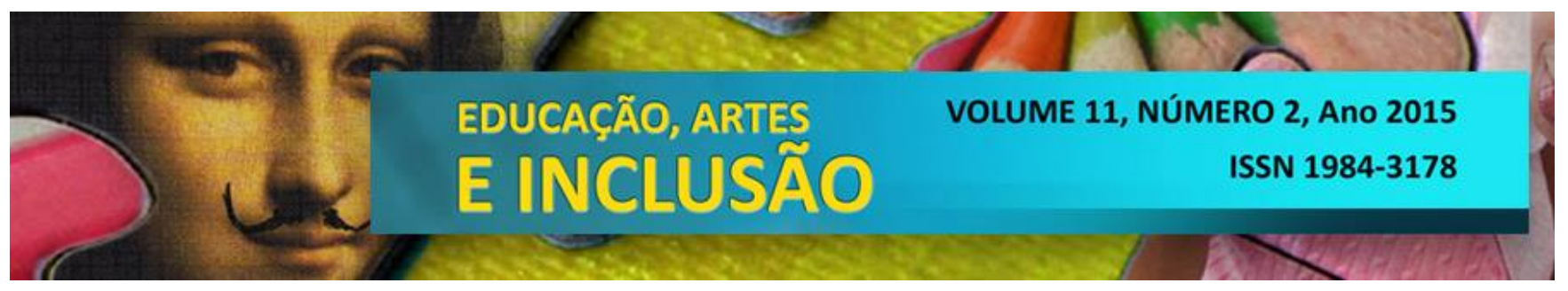

\title{
LIBRAS NA ÁREA DE CIÊNCIAS NATURAIS: BUSCA POR ARTICULAÇÃO ENTRE CONHECIMENTOS
}

\section{BRAZILIAN SIGN LANGUAGE IN THE NATURAL SCIENCES FIELD: SEARCH FOR ARTICULATION BETWEEN ACQUIREMENTS}

DOI: http://dx.doi.org/10.5965/198431781122015008

\author{
Francisca Melo Agapito - UFMA \\ Andreia Aparecida Guimarães Strohschoen - UNIVATES \\ Maria Isabel Lopes - UNIVATES \\ Marcelo Franco Leão - IFMT
}

\begin{abstract}
RESUMO
A disciplina de Língua Brasileira de Sinais (Libras) atualmente é uma exigência legal. Nesse sentido, o objetivo deste texto é apresentar algumas reflexões acerca das percepções de alunos do curso de Ciências Naturais de uma instituição de ensino superior no município de Imperatriz-MA sobre o aprendizado de sinas da Libras na área de ciências. O estudo se configura como uma pesquisa-ação, com abordagem qualitativa e pautada na análise de conteúdo. A investigação revelou a importância de se empreender o estudo da Libras na área de ciências naturais, visando oportunizar aos alunos surdos tais conhecimentos. Inferiu-se ainda que a construção de aportes teóricos e práticos na área da Libras aos futuros educadores é possível, proporcionando aprendizagens significativas na área de ciências.
\end{abstract}

PALAVRAS-CHAVE: Ciências naturais, Libras, Formação de professores.

\begin{abstract}
The Brazilian Sign Language course (Libras) is currently a legal requirement. Accordingly, the purpose of this paper is to present some reflections on the perceptions of Natural Sciences students of a higher education institution in Imperatriz-MA city about learning resins Libras in science. The study is configured as an action research with qualitative approach and guided the content analysis. Research has shown the importance of undertaking the study of Libras in the field of natural sciences, aiming to create opportunities for deaf students such knowledge. It is also inferred that the construction of theoretical and practical contributions in the field of Libras to future educators is possible, providing meaningful learning in science.
\end{abstract}

KEYWORDS: Natural Sciences, Pounds, Teacher training. 


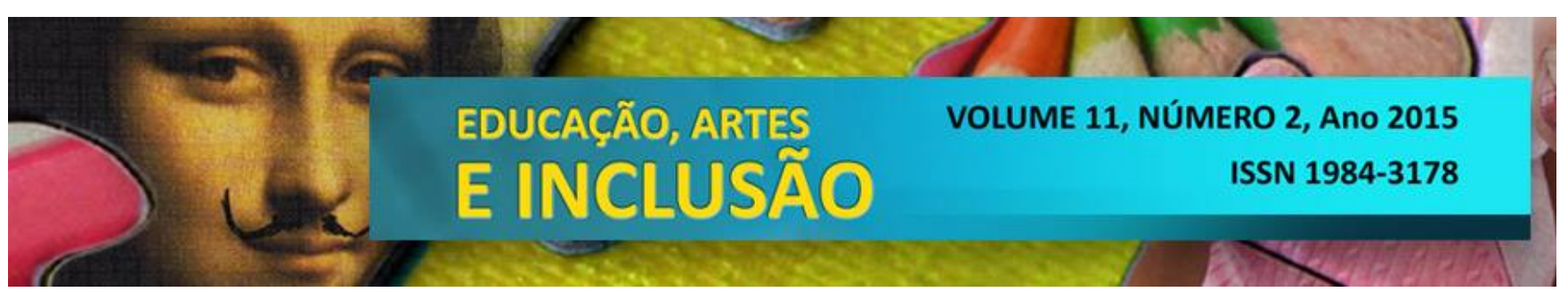

\section{Introdução}

As mudanças nas legislações em prol da inserção da Língua Brasileira de Sinais $(\mathrm{LSB})^{1}$ ou Libras como disciplina no ensino superior, trouxe a tona, a necessidade de futuros docentes terem conhecimentos acerca dessa língua, bem como conhecimentos sobre a pessoa surda. $O$ artigo $3^{\circ}$ do decreto $n^{-0} 5.626 / 05$ diz que "A Libras deve ser inserida como disciplina curricular obrigatória nos cursos de formação de professores para o exercício do magistério, em nível médio e superior, e nos cursos de Fonoaudiologia, de instituições de ensino, públicas e privadas [...]" (BRASIL, 2005).

Diante deste cenário, durante o processo formativo, deve ser oportunizado o aprendizado sobre essa língua como objeto de estudo aos futuros profissionais, visto que, pessoas surdas, conforme a Política Nacional da Educação Especial na Perspectiva da Educação Inclusiva têm o direito de estar incluída com os demais alunos ditos normais e ter oportunidades igualitárias de construção de conhecimentos (BRASIL, 2008).

Diante do exposto, o objetivo do presente trabalho foi verificar a percepção junto a alunos do curso de ciências naturais, sobre o aprendizado de sinais da Libras voltados para sua área de formação e atuação, bem como identificar se houve uma aprendizagem significativa, com vistas a promover acepções mais claras e consistentes sobre a Libras e a pessoa surda no decorrer da disciplina. Pontua-se então, que esta investigação é resultado dos estudos realizados com alunos do curso de ciências naturais de uma instituição de ensino superior em Imperatriz-MA, com a disciplina de Libras, que teve uma duração total de 45 horas/aula.

Apresenta-se então, uma breve abordagem teórica sobre a Libras, algumas características que reafirmam seu status linguísticos, além de evidenciar sua relevância para o processo de desenvolvimento da pessoa surda. Logo em seguida, são destacados os procedimentos metodológicos e resultados deste estudo.

\footnotetext{
${ }^{1}$ LSB- Língua de Sinais Brasileira é a sigla utilizada e reconhecida em âmbito internacional, conforme os padrões de identificação para as línguas de sinais.
} 


\section{Língua Brasileira de Sinais - Libras: buscando alguns conceitos}

Para todos os grupos sociais, ter acesso à informação, à construção de conhecimentos e integração na sociedade; são fatores de extrema relevância para que ocorra de modo efetivo o desenvolvimento humano, de modo que, a partir dessa premissa, enfocando a realidade de pessoas surdas, identificar e compreender determinadas particularidades, formas de apreensão do conhecimento, dentre outros aspectos, torna-se indubitável para a promoção de sua emancipação.

Outrossim, um dos mecanismos para que a pessoa surda possa adquirir sua independência é por meio da sua língua materna, Libras, que é a língua de sinais utilizada pela comunidade surda brasileira para se comunicar com surdos e ouvintes fluentes nesta língua.

Fernandes e Correia (2012) explicam que "a língua de sinais é o sistema mediador do surdo por excelência”, pois traduz do melhor modo possível o processo de apreensão de conhecimentos. Sobre esse aspecto os autores enfocam que o conceito semiótico explica essa afirmativa ressaltando que:

Em uma perspectiva semiótica, a língua de sinais deve ser observada não apenas como a língua de uma minoria linguística, mas por sua natureza e peculiaridades de estruturação e representação que são próprias de um sistema significante distinto da linguagem verbal articulada (FERNANDES; CORREIA, 2012, p. 221).

Esse viés denota o quanto os processos para a aquisição das línguas de sinais são aprofundados, e devem ser considerados todos os pontos que originam suas representações para que as experiências cognitivas sejam construídas de modo pleno. Ademais, a Libras para a pessoa surda é a forma natural de comunicação, é por meio dela que a pessoa surda manifesta sua cultura, sua identidade, seus anseios e desejos, se faz entender sem constrangimentos e com a segurança de ser nativo em sua língua de origem.

Nas palavras de Harisson (2014, p. 31) ao representar as línguas de sinais destaca que estas "são produzidas por movimentos das mãos, do corpo e expressões faciais em um espaço à frente do corpo, chamado de espaço de sinalização. A pessoa "recebe" a sinalização pela 


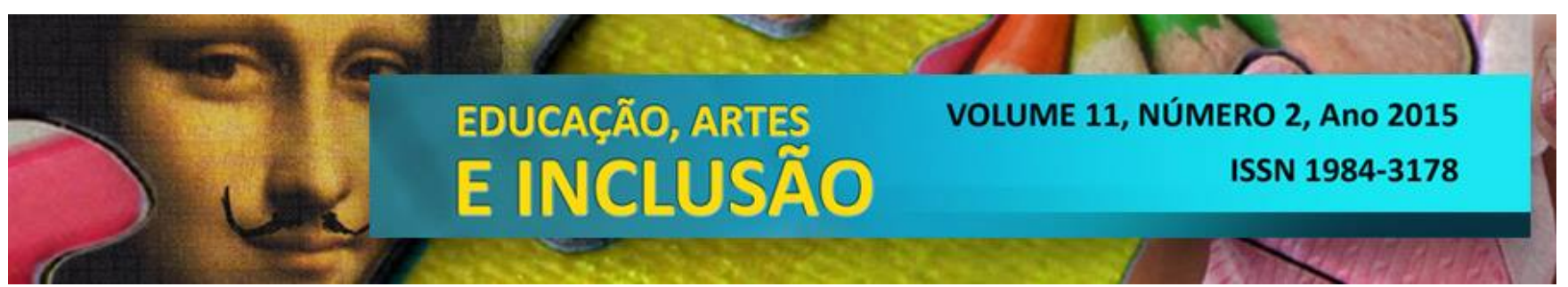

visão, razão pela qual as línguas de sinais são chamadas de visuoespaciais ou espaço-visuais". Característica esta que potencializa a possibilidade de desenvolvimento do surdo.

Bakhtin (2006) explica que o ato da comunicação se faz por meio da palavra, ela procede de alguém e se dirige a alguém, é por meio desta que ocorre a interação verbal, servindo inclusive de ponte entre as pessoas e exercendo um papel relevante nas relações sociais, ou seja, de um em relação ao outro e na coletividade.

Nessa ótica, é por meio da palavra que as pessoas interagem, se manifestam acerca de seus anseios, angústias, raivas, dentre outros aspectos, em relação ao outro. Seguindo esse raciocínio, fica clara a necessidade da língua para que as relações sociais ocorram plenamente, no caso do surdo, essa palavra é identificada por meio de sinais ${ }^{2}$, próprios da Libras.

Ressalta-se também que, um fator de extrema relevância deve ser considerado em se tratando da sua língua materna, a Libras, esta é natural, Quadros (2004, p. 30) explica que "as línguas de sinais são consideradas línguas naturais e, consequentemente, compartilham uma série de características que lhes atribui caráter específico e as distingue dos demais sistemas de comunicação" e como qualquer outra língua tem peculiaridades próprias, constituindo-se um sistema linguístico com inúmeras características.

Ao discorrer sobre língua de sinais, Ferreira (2010, p.16) ressalta que "considerandose a importância de uma língua para o seu usuário nativo e para a comunidade que a usa, acreditamos que só mesmo um respeito à língua de sinais conduzirá a um maior sucesso educacional e social do surdo".

Concomitante a isso, cabe ressaltar de acordo com a afirmação de Bourdieu (2008, p. 49) que "o domínio da língua legítima pode ser adquirido pela familiarização, ou seja, por uma exposição mais ou menos prolongada à língua legítima ou pela inculcação expressa de regras explícitas", isso exprime dizer que os principais meios para a aquisição competente da

\footnotetext{
${ }^{2} \mathrm{Na}$ Libras, os sinais representam as palavras na Língua Portuguesa (Pimenta e Quadros, 2009).
} 


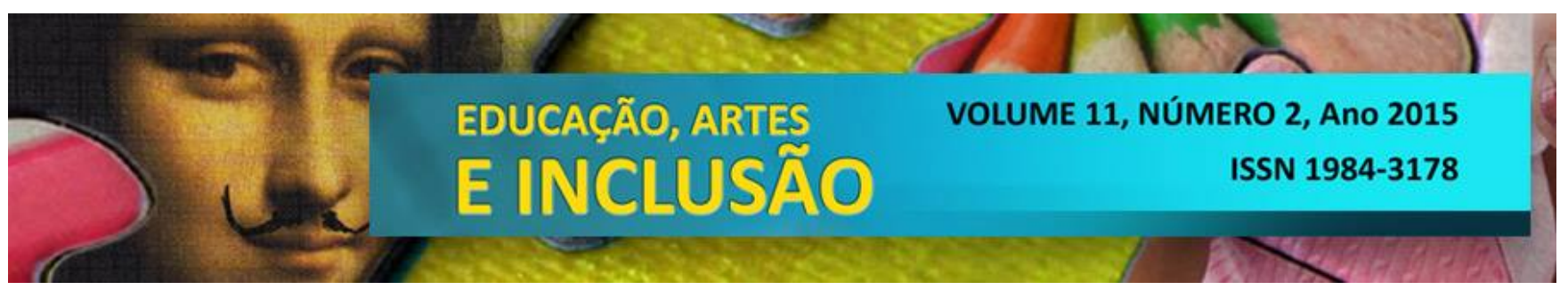

língua são a família e a escola, posto isto, a pessoa surda necessita ter contato com sua língua materna no ambiente familiar e escolar.

Para Moura (2014) a Libras exerce papel fundamental na aprendizagem de alunos surdos, sua situação prioritariamente visual contempla as necessidades de comunicação, informação e cognição. A autora esclarece ainda que "[...] do ponto de vista linguístico, as línguas de sinais são consideradas línguas verdadeiras desde o estudo pioneiro de Stokoe sobre a língua de sinais”.

Trazendo essa discussão para a perspectiva social verifica-se ainda que a comunidade surda utiliza e segue as regras básicas de manutenção semântica e sintática dessa língua, situação que agrega valor social, autonomia e legitimação ao agrupamento que a usa (ibid, 2014).

Ademais, ao descrever a relevância da língua de sinais Campos (2014, p. 57) pontua que "[...] o aluno surdo necessita da língua de sinais para que haja possibilidade de diálogo, expor suas dúvidas e ter troca de ideias para a construção de seu conhecimento, e também para a obtenção de informações importantes e conteúdos das aulas". Ratificando nos aspectos aqui mencionados seu papel para a pessoa surda.

Portanto, fica demonstrada a relevância da Libras como uma língua essencial para o desenvolvimento social, cognitivo e pessoal, além de esta ser o meio mais eficaz para a elaboração dos processos mentais, para a efetivação das relações sociais, experiências significativas e crescimento profissional do surdo.

\section{Materiais e métodos}

Este estudo se configurou como uma pesquisa-ação, e embasada em categorias de análises. De acordo com Fiorentini (2010, p. 72), a pesquisa-ação “[...] torna o participante da ação um pesquisador de sua própria prática e o pesquisador um participante que intervém no rumo da ação, orientado pela pesquisa que realiza [...]”. Logo, entende-se que este tipo de 


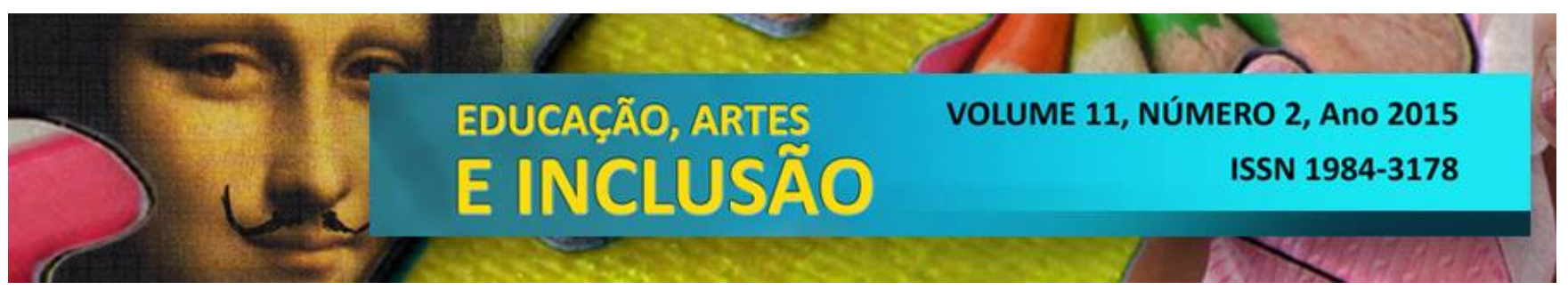

pesquisa se adequa aos objetivos propostos nessa investigação. O estudo tem uma abordagem qualitativa, Gerhardt (2009), aponta que a pesquisa qualitativa preocupa-se com aspectos da realidade que não podem ser quantificados, buscando a compreensão e explicação da dinâmica das relações sociais.

A pesquisa foi realizada instituição de ensino superior no município de ImperatrizMA, com acadêmicos do $6^{\circ}$ período do curso de Ciências Naturais no semestre 2014.3 (período intensivo de aulas, referente às disciplinas ministradas no mês de julho). Fizeram parte desta investigação quatro mulheres e dois homens, totalizando 06 alunos. Para a escolha dos participantes foi utilizado o critério de intencionalidade em que pesa: está regularmente matriculado na disciplina de Libras e está frequentando as aulas. Além do critério de acessibilidade, que possibilitou um dinamismo na coleta de dados.

Para possibilitar o desenvolvimento da pesquisa, a direção da instituição assinou a declaração de anuência, permitindo que o presente estudo fosse delineado e a coleta de dados ocorresse de forma coerente. Além disso, os participantes da pesquisa assinaram o termo de consentimento livre e esclarecido (TCLE) ${ }^{3}$ que garantiu o anonimato, a originalidade e seriedade da pesquisa.

A temática referente ao estudo de sinais foi delimitada para conteúdos da disciplina de ciências, que poderiam ser abordados em sala de aula a partir do $7^{\circ}$ até o $9^{0}$ ano. O período para realizar este estudo foi de 16 horas/aula.

Realizou-se, inicialmente, o embasamento teórico sobre o ensino de Libras na área de Ciências Naturais direcionado para a pessoa surda, buscando uma aproximação entre teoria e prática, além de buscar promover acepções mais claras a respeito das peculiaridades linguísticas do surdo. Para o estudo utilizou-se fontes diversificadas, tais como: consultas bibliográficas, artigos de periódicos, dicionários de Libras (impressos e online), e atividades individuais e coletivas.

3 Documento que contém as informações e esclarecimentos éticos referentes à pesquisa. É a manifestação clara de concordância com a participação da pesquisa. 


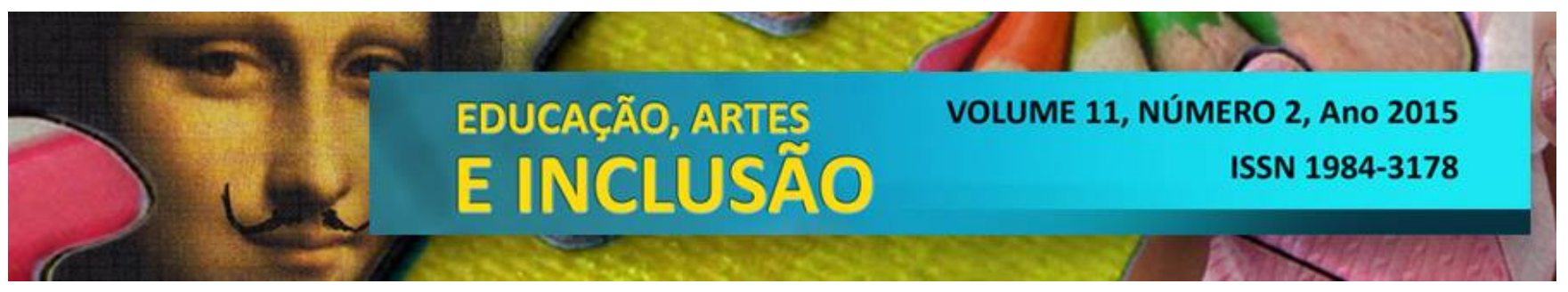

A etapa seguinte foi: solicitar aos alunos que escolhessem um conteúdo de ciências, fizessem um plano de aula que contemplasse as necessidades da pessoa surda, ou seja, principalmente os aspectos visuais. E que a partir da escolha do conteúdo buscassem sinais na Libras referente ao mesmo. Posteriormente, foi solicitado que os alunos realizassem uma aula em Libras a partir dos sinais encontrados.

O tempo previsto foi de 5 minutos, e os alunos ficaram à vontade para utilizar os recursos que considerassem pertinentes. Ao término da atividade proposta, responderam o questionário com questões abertas e fechadas. Dentre as perguntas, aqui são destacados dois questionamentos que se fizeram pertinentes para compreender de modo mais claro as percepções dos acadêmicos sobre a temática em questão. O primeiro foi: Qual a sua percepção sobre o uso de sinais da Libras para o ensino de Ciências? E o segundo foi: De que modo realizar uma aula em Libras contribuiu para o seu aprendizado? As respostas também serviram para apreender a percepção dos participantes da pesquisa.

A análise e discussão dos dados foram baseadas nos referenciais utilizados para a presente pesquisa. As categorizações foram apoiadas na proposta de Bardin (2012), quando esta destaca que surgem categorias de análises. Nesse sentido, a partir das respostas obtidas surgiram três categorias, que serão analisadas conforme a ordem descrita a seguir: Libras no ensino superior; A aprendizagem de sinais na área de ciências naturais; Formação docente e o ensino de pessoas surdas. Com o intuito de preservar a identidade dos participantes da pesquisa, estes foram codificados da seguinte forma: A1, A2, A3... e assim sucessivamente.

\section{Resultados e discussões: Libras no ensino superior}

A partir da inserção da Libras no currículo dos cursos de formação de professores, compreender as percepções de acadêmicos sobre essa realidade torna-se extremamente relevante, visto que sua preparação deve contemplar as necessidades linguísticas da pessoa surda. Nesse sentido, esta categoria expõe, dentre todos os pesquisados, as principais falas de 4 investigados sobre a categoria em análise. 


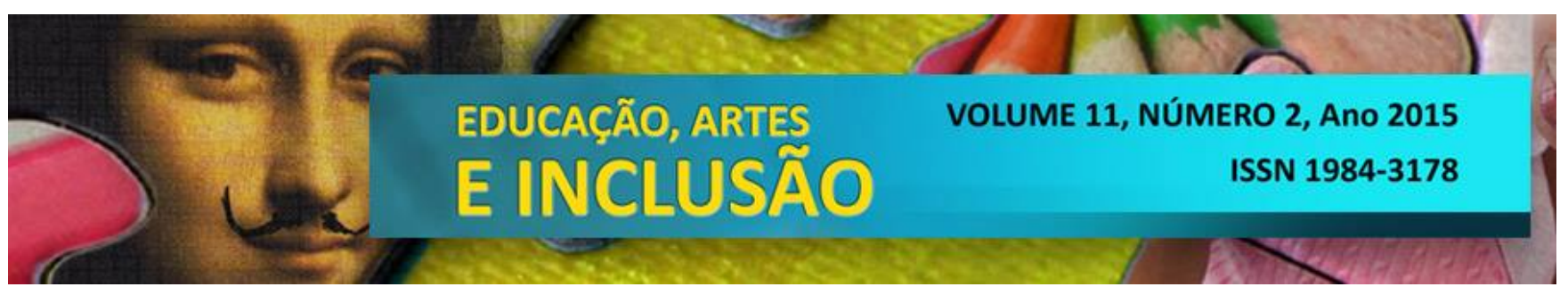

A Libras é uma língua, e a pessoa surda tem o mesmo direito dos demais para obter aprendizagem. [...] Acredito que a lei que ampara essa língua foi muito boa para todos os futuros professores (A1).

Acredito que a inclusão da Libras no ensino superior vai ajudar a todos os futuros professores entender melhor a pessoa surda (A2).

É muito importante ter contato com língua da pessoa surda. [...] se eu tivesse tido esse aprendizado anteriormente, no ensino médio, por exemplo, hoje poderia me comunicar melhor (A4).

Ter a disciplina de Libras no curso de Ciências Naturais poderá proporcionar mais conhecimentos sobre a pessoa surda e sua língua, pois isso é fundamental numa sociedade inclusiva, em que os professores devem estar preparados para atender a todos (A6).

Os relatos dos entrevistados evidencia a tomada de consciência da importância da Libras e de sua inserção no currículo. A realidade de hoje exige que bases, princípios, currículos, enfim, o modelo vigente seja repensado, esta situação é um grande desafio que exige novos modelos e propostas educativas, organização de um bom currículo com um alicerce que permita uma construção de conhecimentos significativos (SILVA, 2009).

A Libras foi oficializada por meio da lei $n^{-}-10.436 / 02$, momento considerado uma conquista para as pessoas surdas usuária dessa língua. Dentre algumas determinações convém enfatizar que a referida lei destaca ainda no Artigo $4^{\stackrel{0}{*}}$.

O sistema educacional federal e os sistemas educacionais estaduais, municipais e do Distrito Federal devem garantir a inclusão nos cursos de formação de Educação Especial, de Fonoaudiologia e de Magistério, em seus níveis médio e superior, do ensino da Língua Brasileira de Sinais - Libras, como parte integrante dos Parâmetros Curriculares Nacionais - PCNs, conforme legislação vigente (BRASIL, 2002).

Segundo o artigo $4^{\circ}$ devem ser implementadas formas de promover a inclusão da Libras como objeto de estudo nos cursos de formação de professores. Sobre esse aspecto A1 destaca que "[...] Acredito que a lei que ampara essa língua foi muito boa para todos os futuros professores". Esse discurso leva ao entendimento de que os acadêmicos tem consciência da necessidade de se prepararem para a posteriori exercem uma prática pedagógica que contemple as necessidades de seus alunos.

Enfim, a elaboração de um currículo que contemple o aprendizado da Libras é de extrema relevância na sociedade brasileira. As políticas públicas vêm direcionando para a 


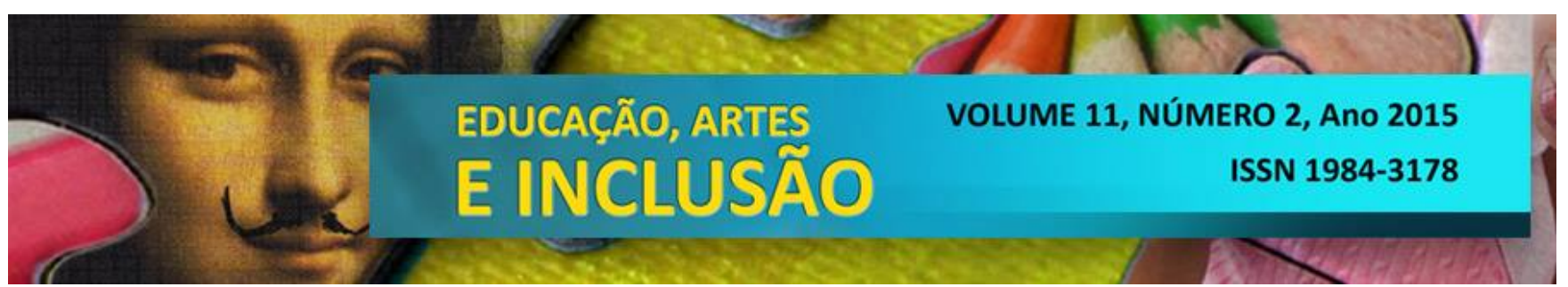

aceitação das diferenças, as exigências legais estão trilhando em direção à igualdade de oportunidades.

Nessa perspectiva, ter nos cursos de formação de professores esta língua como disciplina curricular propicia aos futuros educadores embasamentos para o laboro. Nesse viés, o relato de A6 converge com os preceitos legais que preconizam a busca por uma formação consistente, conforme as exigências da contemporaneidade, principalmente quando esta destaca “[...] os professores devem estar preparados para atender a todos".

Conforme a Resolução CNE/CP nº 1/2002, das Diretrizes Curriculares Nacionais para a Formação de Professores da Educação Básica em nível superior, a formação para a atividade docente, dentre várias orientações, deve promover a preparação para atender a diversidade, seguindo esse raciocínio, o preparo para os futuros profissionais da educação necessita seguir os preceitos da educação para todos.

De acordo com as determinações legais, empreender a preparação de futuros docentes para o ensino que contemple a todos em suas peculiaridades é condição essencial na sociedade vigente. Ainda perspectiva, ter a Libras como uma disciplina nos cursos de formação de professores é um mecanismo indubitável para promover a quebra de barreiras comunicativas entre professores ouvintes e alunos surdos. A partir do discurso de A2 tal percepção é evidenciada "Acredito que a inclusão da Libras no ensino superior vai ajudar a todos os futuros professores entender melhor a pessoa surda". A partir desse discurso, pode-se depreender que a inserção da Libras nos currículos dos cursos de formação de professores pode proporcionar tanto aos surdos quanto aos ouvintes novas construções de conhecimentos e acepções mais claras sobre o surdo e sua língua.

\section{A aprendizagem de sinais na área de ciências naturais}

A disciplina de Libras no curso de Ciências Naturais da instituição pesquisada é bem recente, sendo esta efetivamente ofertada aos alunos em 2013. A segunda turma a ter a oportunidade de aprendizagens com essa disciplina foi a turma em que o presente estudo foi 


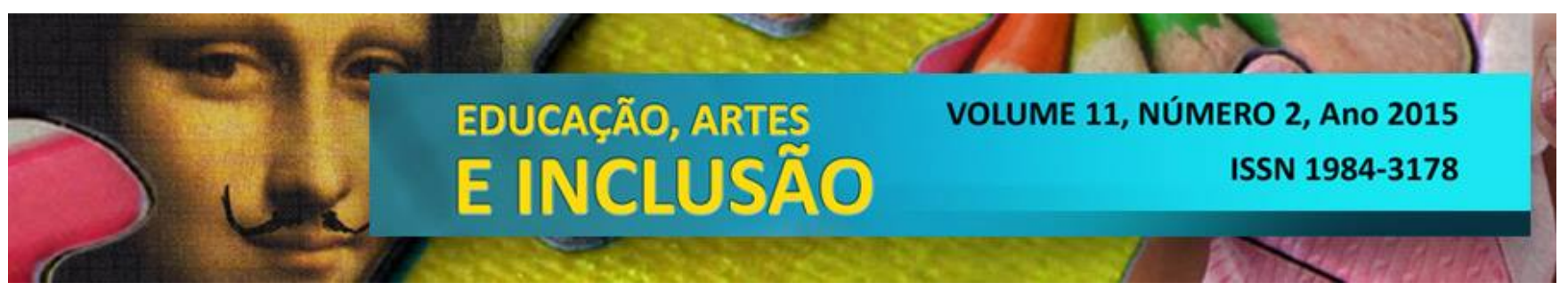

realizado. Por isso refletir sobre as percepções dos acadêmicos acerca da construção de aprendizagens sobre a Libras e consequentemente sobre a pessoa surda, pode proporcionar um maior fortalecimento com vistas a promover a difusão de sinais na Libras para as áreas mais específicas, como ciências, química, física, etc.

Convém destacar que, de forma sucinta, a atividade proposta teve o objetivo de sensibilizar os acadêmicos sobre a pessoa surda e suas especificidades linguísticas, buscar a construção de conhecimentos na área de formação dos acadêmicos, além de propor uma reflexão sobre as possibilidades de desenvolvimento de uma aula em que hajam alunos surdos inclusos.

Seguindo esse raciocínio, convém lembrar que a proposta da educação inclusiva prevê que alunos surdos tenham em sala de aula, o intérprete de Libras. Esse profissional, segundo Quadros $(2004$, p. 27) "É o profissional que domina a língua de sinais e a língua falada do país e que é qualificado para desempenhar a função de intérprete". Alocando este profissional em âmbito educacional, sua inserção em sala de aula terá como um de seus papeis mediar à comunicação entre alunos ouvintes e surdos, professores e alunos surdos, ou seja, o aparato desse profissional para interpretar e traduzir suas aulas é hoje um direito legal.

A seguir são destacadas as falas de todos os acadêmicos pesquisados, visto que o aprendizado proposto na atividade de planejamento e realização de uma aula por meio da Libras, foi um dos pontos a serem analisados para contemplar o objetivo dessa investigação.

O planejamento foi mais fácil, as aulas prévias da professora trouxeram embasamentos para a construção. [...] já para os sinais de ciências, senti um pouco de dificuldade porque não conhecia a Libras (A1).

Fiquei muito ansiosa para realizar a atividade, busquei sinais sobre a temática "plantas". No final acredito que consegui realizar de modo satisfatório. [...] posso afirmar, foi muito bom para entender e se colocar no lugar da pessoa surda e das suas necessidades (A2).

$\mathrm{Na}$ minha concepção todos os futuros professores devem passar por um momento como esse [...]. Aprendi muito, principalmente compreender melhor a pessoa surda (A3).

Foi um pouco difícil aprender os sinais, alguns eu não imaginava que realmente tinha tradução. [...] no meu entendimento é muito importante pontuar que é uma necessidade para os professores em todos os níveis 


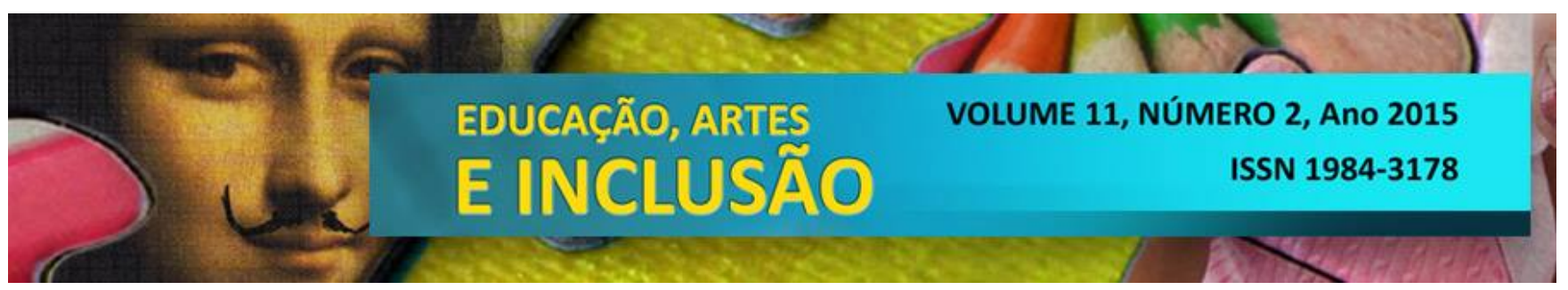

educacionais e para a sociedade como um todo aprender a respeitar as pessoas surdas (A4).

Foi um desafio a realização da atividade porque é uma realidade nova para a maioria dos futuros docentes. Senti um pouco de dificuldade para aprender alguns sinais da área de ciências, mas foi uma experiência enriquecedora para a minha formação (A5).

$\mathrm{O}$ aprendizado de sinais na área de ciências naturais me proporcionou a construção de um novo olhar em relação à pessoa surda e as possibilidades visuais que podem auxiliar a pessoa surda no aprendizado. Não conhecia a Libras e nem sabia que poderia aprender tantos sinais específicos, porém também percebi que muitos sinais ainda precisam ser organizados, termos que só encontrei na datilologia [...] (A6).

A partir dos discursos dos pesquisados, ficou clara a motivação dos alunos para a realização da atividade, que proporcionou um bom andamento da atividade, haja vista estes se lançaram ao desafio de planejar uma aula e realizá-la em Libras, mesmo não tenho fluência nessa língua.

A proposta da atividade para a apreensão de sinais na área de formação dos acadêmicos impactou-os no sentido de repensarem as singularidades existentes em sala de aula além de proporcionar uma reflexão acerca da relevância da preparação para atuação docente. Sobre esse aspecto, A6 relata "O aprendizado de sinais na área de ciências naturais me proporcionou a construção de um novo olhar em relação à pessoa surda e as possibilidades visuais que podem auxiliar a pessoa surda no aprendizado".

No tocante a situação destacada por A6, destaca-se que, por ser uma disciplina relativamente nova, em muitos currículos, e boa parte da população desconhecer as características inerentes à pessoa surda, discursos e construções de conhecimentos sobre as particularidades do surdo, sua língua, sua cultura, enfim, se fazem presentes nos discursos daqueles que ainda não tiveram a oportunidade de conhecer esse grupo específico.

Acrescenta-se que o aprendizado de sinais voltados para a formação dos acadêmicos, possibilitou também um novo olhar que se expressa na possibilidade de construir significados referentes ao surdo e sua língua. 


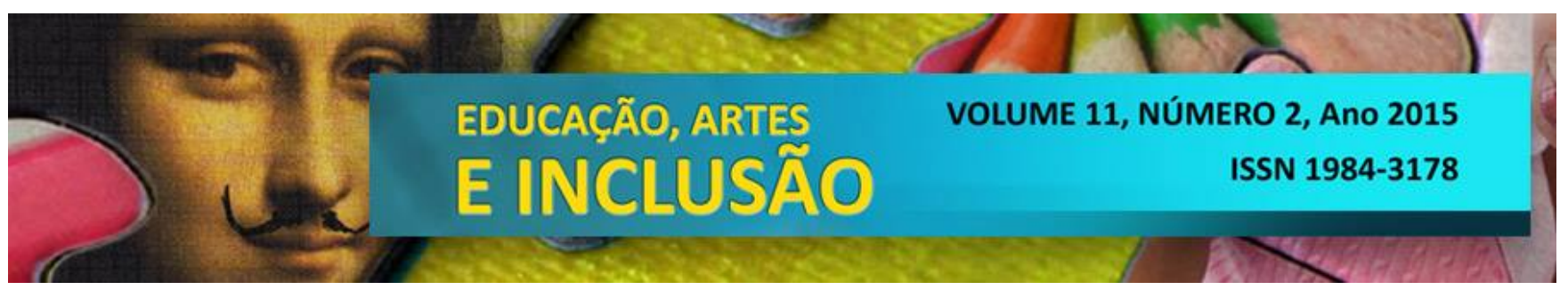

Corroborando com o discurso de A6, Masetto (2012) explica que atualmente o professor deve ser um mediador no processo de aprendizagem de seus educandos, buscando situações de aprendizagem que provoque reflexão e construções de conhecimentos. Urge então, oportunizar tessituras coerentes com as possíveis práticas que serão exigidas em âmbito educacional é abarcar o paradigma da diferença em prol da igualdade de oportunidades para todos.

Os discursos dos acadêmicos remete também ao fato de que há a necessidade de se difundir que a Libras possui todas as características necessárias para atender a uma comunicação eficaz e dinâmica. Em relação aos aspectos linguísticos, Felipe (2006, p. 20) explicita que:

Como toda língua, as línguas de sinais aumentam seus vocabulários, com novos sinais introduzidos pelas comunidades surdas, em resposta às mudanças culturais e tecnológicas, assim a cada necessidade surge um novo sinal desde que ele se torne aceito, sendo utilizado pela comunidade.

Como qualquer outra língua oral e auditiva, as línguas de sinais contemplam as necessidades de comunicação das pessoas. Além disso, possui todos os elementos linguísticos fundamentais que a legitimam como língua. Ademais, torna-se cada vez mais relevante um trabalho que permita refletir, discutir, problematizar, enfim, propor novas construções referentes a esse grupo minoritariamente linguístico.

Falas como a de A3"Aprendi muito, principalmente compreender melhor a pessoa surda"; e A4 "Foi um pouco difícil aprender os sinais, alguns eu não imaginava que realmente tinha tradução", são exemplos da situação descrita anteriormente. As percepções destes pesquisados trazem a tona alguns mitos que ainda perduram na sociedade, tais como: a Libras não é uma língua; não há sinais para uma comunicação eficiente; não sei por que o surdo não aprende a Língua Portuguesa, dentre outros.

Explorar situações como estas são indubitáveis para favorecer construções mais conscientes sobre o surdo e sua língua. Promover, a partir das vivências e sensações dos alunos, posicionamentos que se entrelacem com a perspectiva legal que a sociedade vislumbra, é um mecanismo salutar na medida em que podem propiciar criticidade e pro- 


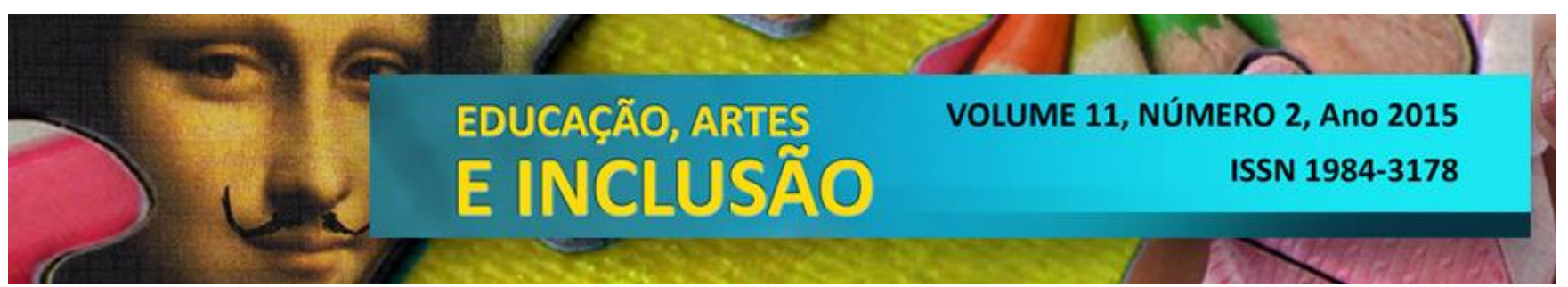

atividade a estes sujeitos, que posteriormente poderão contribuir com a formação de cidadãos críticos e reflexivos. E mais especificamente em se tratando da formação dos acadêmicos para o ensino de ciências, englobar a perspectiva do ensino que inclua o surdo nesse processo também se faz essencial.

Referente ao aprendizado de sinais específicos da área de ciências foi notório que, colocar os acadêmicos frente às situações que podem tornar-se realidade no cotidiano de sala de aula, provocou nestes algumas reflexões sobre a Libras e sua formação para o ensino de ciências. Para exemplificar o exposto anteriormente, pontua-se A5 ao discorrer "Senti um pouco de dificuldade para aprender alguns sinais da área de ciências [...]”. Já A1 enfatizou [...] para os sinais de ciências, senti um pouco de dificuldade porque não conhecia a Libras (A1).

A situação descrita pelos pesquisados ainda é bastante comum, pois o contato com a Libras é mais comum para pessoas que participam da comunidade surda, profissionais que lidam diretamente com surdos usuários dessa língua e famílias que têm membros surdos. Para Padden apud Felipe (2007, p. 45) "uma comunidade é um sistema social geral, no qual pessoas vivem juntas, compartilham metas comuns e partilham certas responsabilidades umas com as outras". Na visão da autora, as vivências e metas são comuns, e as pessoas partilham dos mesmos objetivos. Em relação à língua não é diferente, ou seja, interagem por meio da língua.

Soma-se a isto, o fato de que a Libras como objeto de estudos foi inserida na proposta curricular de formação de professores há pouco tempo. Tal situação representa um dos resquícios do processo histórico pelo qual a pessoa surda esteve envolta. É importante frisar que, dentre várias situações, a proibição das línguas de sinais foi e ainda é um dos principais motivos do desconhecimento das pessoas.

Nas palavras de Veloso e Maia (2009, p. 45) "A língua de sinais, em todas as suas formas, foi proibida oficialmente, estigmatizada alegando que a mesma destruía a capacidade de fala dos surdos [...]". Nessa ótica, a partir da fala dos autores, fica claro que as angústias descritas pelos participantes da pesquisa são justificadas e entendidas, visto que por um longo 


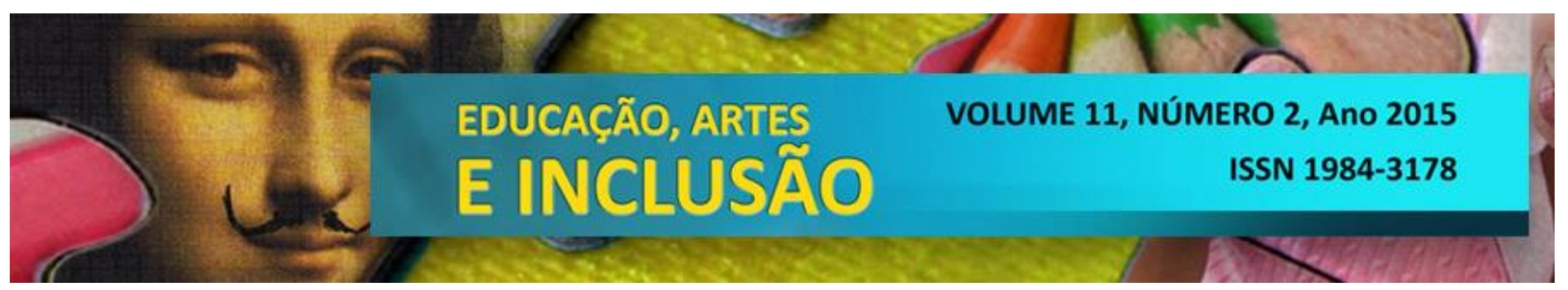

período a sociedade da época impediu a difusão e o desenvolvimento das línguas de sinais.

Contudo, é indubitável relatar acerca das angústias destacadas sobre a necessidade de ter sinais da área de ciências que ainda não foram sistematizados, precarizando o desenvolvimento da aula e o processo de aprendizagem de alunos surdos. Sobre essa situação (A6) descreve "porém também percebi que muitos sinais ainda precisam ser organizados, termos que só encontrei na datilologia [...]”. O depoimento do entrevistado vai ao encontro do fato de que a Libras, igualmente as demais línguas de sinais espalhadas pelo mundo sofreram prejuízos imensuráveis, acarretando situações como a destacada anteriormente.

Para Caetano e Lacerda (2014, p. 220) esse processo encontra uma explicação plausível, visto que "[...] toda língua se desenvolve e se amplia segundo a demanda de seus usuários, o que é recente na Libras, uma vez que até bem pouco tempo atrás pouquíssimos surdos chegavam ao ensino superior e tinham necessidades de conhecimentos técnicos". De modo que ainda são necessárias ações que sistematizem e viabilizem a difusão destes sinais para que a aprendizagem de alunos surdos seja mais significativa nessa área que é de suma importância.

Em suma, torna-se imprescindível na sociedade atual, possibilitar uma formação que, abarque as exigências da contemporaneidade, promovendo momentos sistemáticos em que os alunos poderão obter mais embasamentos sobre a Libras, a pessoa surda, dentre outros, e preconizando experiências voltadas para uma formação pedagógica e específica dos futuros professores, contemplando mesmo que de forma elementar a atuação em sala de aula atendendo a pessoa surda em suas especificidades.

\section{Formação docente e o ensino de pessoas surdas}

Para os professores ter formação consistente é uma necessidade na sociedade atual, a velocidade com que as informações chegam, as exigências mercadológicas que priorizam profissionais qualificados fazem do processo formativo um importante elemento para o desenvolvimento dos indivíduos nesse novo formato social em que as transformações no 


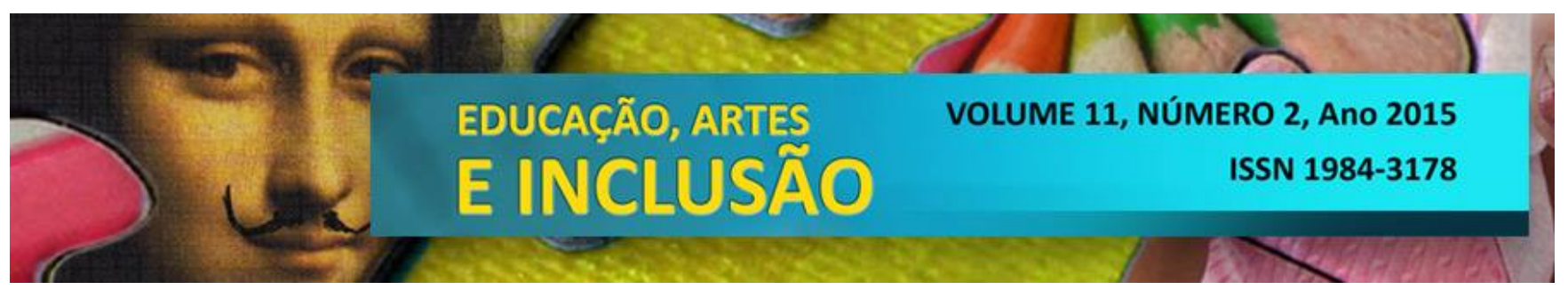

mundo científico, as tecnologias, enfim, ocorrem de forma dinâmica (GARCÍA, 2009).

Convergindo com a ideia descrita acima e retomando o atual cenário de ensino voltado ao aluno, à formação de professores necessariamente deve ser reorganizada para explorar nos futuros profissionais competências para mediar o ensino, proporcionando a aquisição de valores, atitudes, habilidades, dentre outros fatores.

Diante desse novo panorama, foram selecionadas as principais falas de 3 pesquisados sobre a categoria em análise:

\begin{abstract}
A formação de professores necessita promover embasamentos para a vida profissional de forma genérica e para a área específica de formação. Referente à pessoa surda não é diferente, por isso adquirir conhecimentos sobre a Libras é fundamental [...] (A3).

$\mathrm{Na}$ atualidade ter formação coerente com as exigências da sociedade permite a nós futuros educadores ter mais segurança para encarar uma sala de aula com toda a heterogeneidade existente, e nesse meio, as pessoas surdas também estão inseridas, de modo que, é essencial aprender mesmo que superficialmente sobre sua língua e seu modo de aprender (A5).

Considero muito complexo o ensino de pessoas surdas, por isso aprender sobre suas características permitirá otimizar seu aprendizado. [...]. Ter oportunidade de vivenciar um pouco a realidade da surdez por meio da disciplina de Libras, me fez refletir sobre a relevância desse aprendizado para minha atuação em sala de aula (A6).
\end{abstract}

A partir das falas dos acadêmicos investigados, depreende-se que há o entendimento de todos sobre a realidade atual em que a partir das transformações ocorridas na atualidade exigem uma formação mais dinâmica. Na concepção de Imbernón (2006), a formação de professores na educação contemporânea deve ser baseada numa perspectiva holística, tendo como eixo a construção crítica, reflexiva para a participação na sociedade na qual está inserida.

A situação acima descrita encontra-se na fala de A5 "Na atualidade ter formação coerente com as exigências da sociedade permite a nós futuros educadores ter mais segurança para encarar uma sala de aula com toda a heterogeneidade existente". Nesse contexto, percebe-se uma aproximação entre os referenciais teóricos e a percepção descrita do pesquisado, denotando que as construções advindas do processo acadêmico estão em conformidade com a sociedade vigente. 


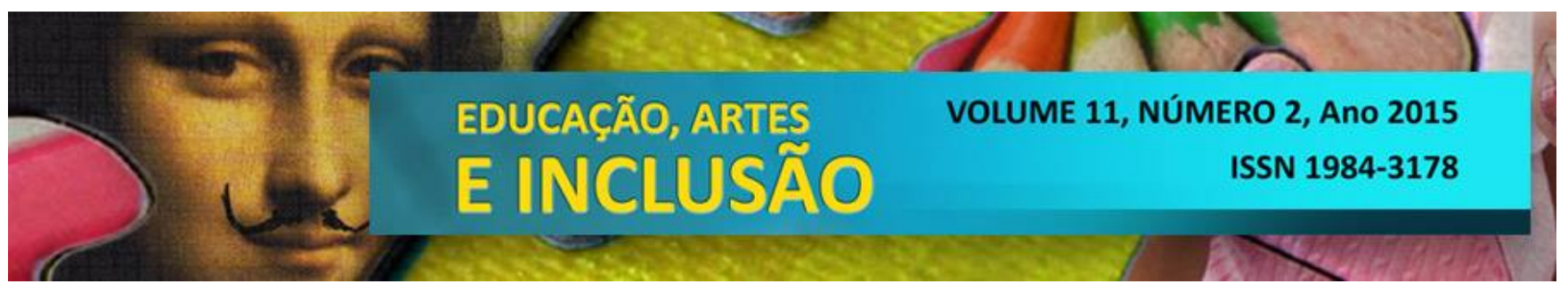

No que diz respeito à formação docente na atualidade, com efeito, a fala de A6 vai ao encontro do que se busca suscitar para o exercício docente. O investigado pontua "Considero muito complexo o ensino de pessoas surdas, por isso aprender sobre suas características permitirá mediar seu aprendizado (A6)”. Em consonância ao destacado acima, Masetto (2012) explica que o perfil do professor alterou-se significativamente, o profissional que antes era um especialista no laboro de transmitir o conhecimento, passou a ser um mediador de aprendizagem.

Semelhante a isso, A3 expõe "A formação de professores necessita promover embasamentos para a vida profissional de forma genérica e para a área específica de formação". Para Tardif (2012), seria extremamente significativo que a formação de professores fosse pautada em situações significativas e se aprofundasse em conhecimentos gerais e específicos de sua profissão. Notadamente, fica evidente que atualmente, promover aos futuros educadores uma percepção holística das situações de aprendizagens se faz emergente.

Buscando trilhar um caminho articulado entre os conhecimentos genéricos e específicos para a atuação em sala de aula e mediante o terreno sinuoso que ainda se apresenta em relação à pessoa surda, suscitar conhecimentos referentes a este ser, é um veio conduto para potencializar as ações em prol de seu desenvolvimento cognitivo, social e educacional. Seguindo esse raciocínio, A3 confirma sobre o discorrido anteriormente ao relatar "Referente à pessoa surda não é diferente, por isso adquirir conhecimentos sobre a Libras é fundamental $[\ldots]^{\prime \prime}$.

O discurso acima traz a tona também o fato de que a educação inclusiva propõe que todos os envolvidos nesse processo estejam comprometidos com a aprendizagem de seus educandos, quebrando barreiras comunicativas e permitindo assim o acesso ao conhecimento destes (CAMPOS, 2014).

Ainda nesse sentido, convém enfatizar que nesse processo a formação de professores deve procurar fomentar a construção de posicionamentos a partir da educação inclusiva, com 


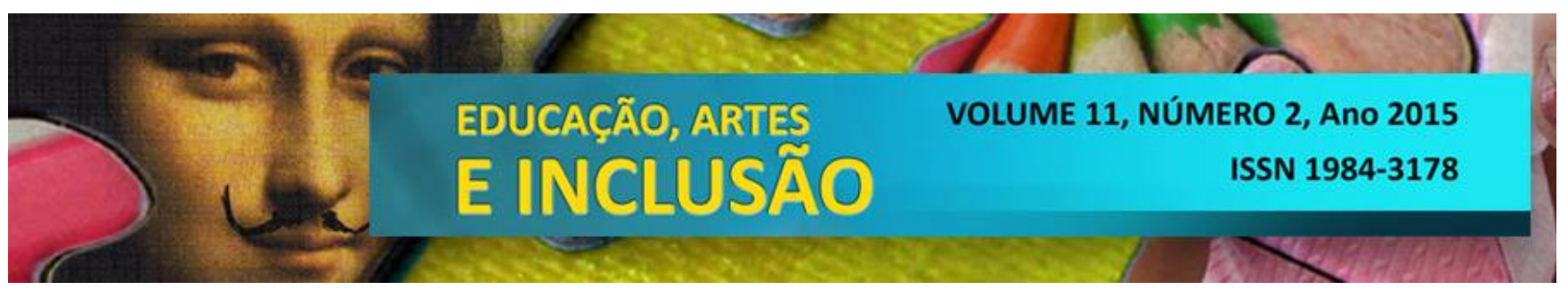

vistas a reconhecer às especificidades, os recursos necessários, as dificuldades, enfim, um aparato teórico para oferecer um atendimento de qualidade aos alunos surdos.

Diante do exposto, fica ratificada a relevância de gerar aos futuros professores conhecimentos referentes à temática da surdez e da Libras. A partir da interlocução entre os saberes necessários para uma formação consistente, a prática pedagógica de docentes para o ensino de ciências nas diversas situações educacionais poderá tornar-se cada vez mais significativa para a diversidade existente em sala de aula.

\section{Considerações Finais}

Consolidar a Libras como uma língua que necessita de ser ensinada e difundida nas diversas áreas de conhecimentos é primordial, na medida em que a cada dia, os surdos se fazem presentes nos mais variados setores da sociedade. As pessoas surdas estão ávidas para utilizarem sua língua materna de forma efetiva. Nesse panorama, as formações de professores vêm convergir com os esforços legais para impulsionar a oportunidades de comunicação, socialização e construção de conhecimento para surdos e ouvintes.

A evolução da Libras no meio acadêmico é outro ponto a ser enaltecido, a exemplo sua inserção no ensino superior no cursos de licenciatura. A possibilidade para que os futuros educadores adquiram conhecimentos sobre essa língua, e assim possam trilhar um caminho profissional com condições mínimas de atender de forma mais igualitária a essa parcela da população.

A lei $n^{0}$ 9394/96 destaca que no ensino superior a formação de profissionais de nível superior, deve dentre vários aspectos, contemplar o cultivo do saber humano, como destaca o artigo $52^{\circ}$, inciso I "produção intelectual institucionalizada mediante o estudo sistemático dos temas e problemas mais relevantes, tanto do ponto de vista científico e cultural, quanto regional e nacional;" (BRASIL, 1996). 


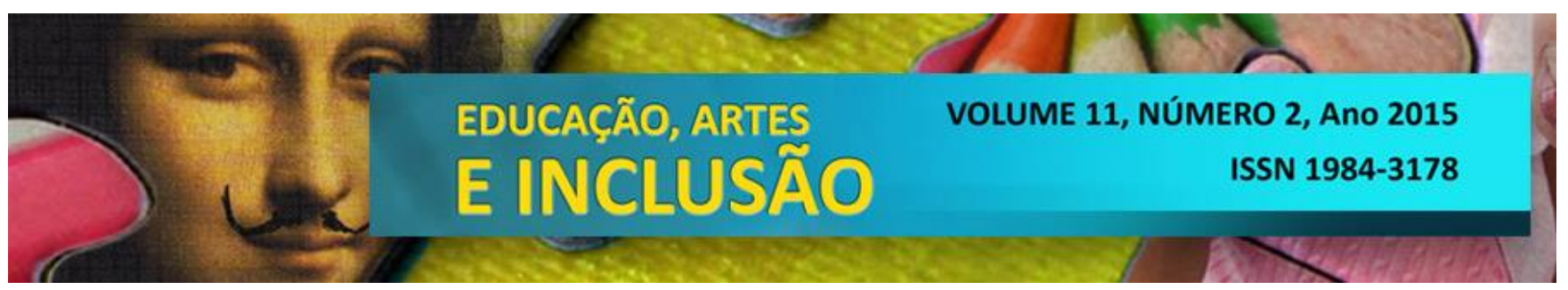

Portanto, forjar situações de aprendizagens na academia aos futuros educadores, com aportes teóricos apropriados para sua prática pedagógica é condição essencial na sociedade contemporânea. Referente ao ensino de Libras, tal intento se configura uma ação promotora da igualdade de oportunidades e desenvolvimento dos surdos.

A pesquisa revelou que, pelo fato da Libras ser relativamente nova como objeto de estudo, nos diversos cursos de formação de professores, se faz urgente promover mais situações de aprendizagens aos acadêmicos dos cursos de formação de professores. Além disso, foi possível inferir que no ensino de ciências, esta língua se apresenta com inúmeras possibilidades para que os educadores possam mediar à construção de conhecimentos significativos aos surdos, possibilitando a estes, maior clareza sobre essa área de conhecimento que está no entorno de todos nós.

Por fim, fomentar atividades da natureza apresentada nesta pesquisa, pode assentar a difusão, socialização e construção de acepções mais coerentes sobre a Libras, a pessoa surda e suas possibilidades de aprendizado nas áreas de conhecimentos mais específicos, a exemplo, ciências, física, química, dentre outras, desde que haja o preparo e o entendimento dos mediadores para que esse processo ocorra de forma positiva.

\section{Referências}

BAKHTIN, Mikhail Mikhailovitch. Marxismo e Filosofia da Linguagem: problemas fundamentais do método sociológico da linguagem. Trad. Michel Lahud e Yara Frateschi Vieira. 12 ed. São Paulo: Hucitec, 2006.

BARDIN, Laurence. Análise de conteúdo. São Paulo: Edições 70, 2012.

BRASIL. Presidência da República - Casa Civil. Legislação - Lei de Diretrizes e Bases da Educação Nacional, de 20 de dezembro 1996. Estabelece as diretrizes e bases da educação nacional. Disponível em: $<$ http://portal.mec.gov.br/arquivos/pdf/ldb.pdf $>$. Acesso em 25/02/2014 às 15:36.

BRASIL. Presidência da República - Casa Civil. Legislação - Lei n⿳0 10.436, de 24 de 


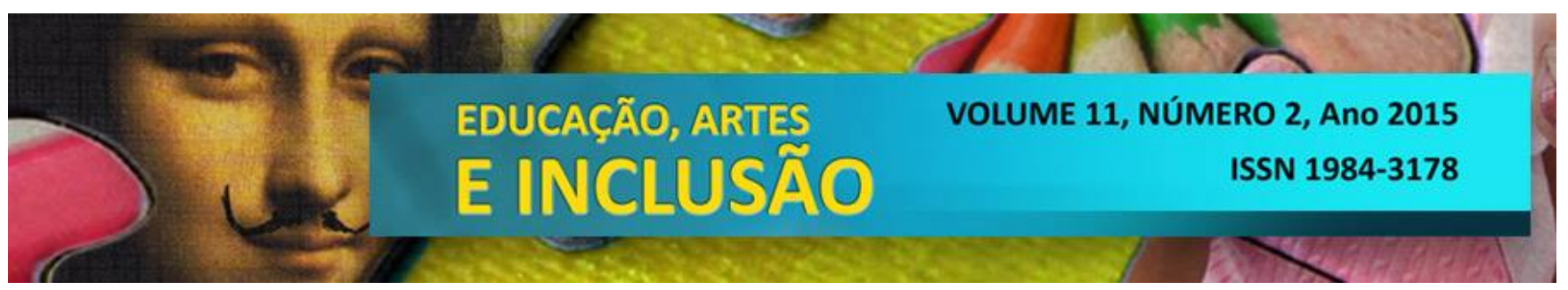

abril de 2002. Dispõe sobre a Língua Brasileira de Sinais - Libras e dá outras providências. Brasília, 2002.

BRASIL, Conselho Nacional de Educação. Resolução CNE/CP 1, de 18 de Fevereiro de 2002. Disponível em: $<$ http://portal.mec.gov.br/cne/arquivos/pdf/rcp01 02.pdf $>$. Acesso em $14 / 11 / 2014$ às $22: 45$.

BRASIL. Presidência da República - Casa Civil. Legislação - Decreto no 5.626, de 22 de dezembro de 2005. Regulamenta a Lei $\mathrm{n}^{\circ} 10.436$, de 24 de abril de 2002, que dispõe sobre a Língua Brasileira de Sinais - Libras, e o art. 18 da Lei $\mathrm{n}^{0} 10.098$, de 19 de dezembro de 2000.Brasília, 2005.

BRASIL, Ministério da Educação. Política Nacional de Educação Especial na Perspectiva da Educação Inclusiva, 2008. Disponível em: $<$ http://portal.mec.gov.br/arquivos/pdf/politicaeducespecial.pdf $>$. Acesso em 09/02/2014 às 10:00.

BOURDIEU, Pierre. A economia das trocas linguísticas: o que falar quer dizer. Prefácio Sergio Miceli. -2 ed. $1^{0}$ reimpr.- São Paulo: Editora da Universidade de São Paulo, 2008.

CAMPOS, Mariana de Lima Isaac Leandro. Educação inclusiva para surdos e a legislação vigente. IN: LACERDA, Cristina Broglia Feitosa de; SANTOS, Lara Ferreira Santos. (Orgs). Tenho um aluno surdo, e agora. Introdução à Libras e educação de surdos. São Carlos: EdUFSCar, 2014.

FELIPE, Tanya Amara. Libras em Contexto: Curso Básico: Livro do Professor. Brasília: Ministério da Educação, Secretaria de Educação Especial, 2006.

Libras em Contexto : Curso Básico : Livro do Estudante. 8ª Edição - Rio de Janeiro : WalPrint Gráfica e Editora, 2007.

FERREIRA, Lucinda. Por uma gramática de língua de sinais. - [reimpr.]. Rio de Janeiro: Tempo Brasileiro, 2010.

FIORENTINI, Dario. Pesquisar práticas colaborativas ou pesquisar colaborativamente. IN: BORBA, Marcelo C; ARAÚJO Juçara L. (Orgs). Pesquisa qualitativa em educação matemática. 3 ed. Belo Horizonte: Autêntica, 2010. 


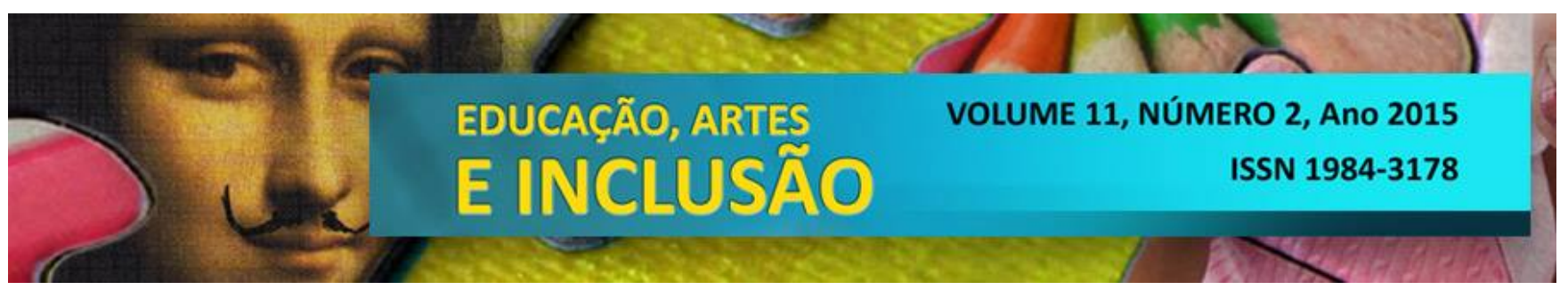

GARCÍA, Carlos Marcelo. Formação de professores: para uma mudança educativa. Tradutora: Isabel Narciso. Porto- Portugal, Porto Editora, 1999.

GERHARDT, Tatiana Engel; SILVEIRA, Denise Tolfo. Métodos de Pesquisa. Porto Alegre: Editora da UFRGS, 2009.

HARISSON, Kathryn Marie Pacheco. Libras: apresentando a língua e suas características. IN: LACERDA, Cristina Broglia Feitosa de; SANTOS, Lara Ferreira Santos. (Orgs). Tenho um aluno surdo, e agora. Introdução à Libras e educação de surdos. São Carlos: EdUFSCar, 2014.

IMBERNÓN, Francisco. Formação docente e profissional: formar-se para a mudança e a incerteza. 6. Ed.- São Paulo, Cortez, 2006.

MASETTO, Marcos Tarcísio. Competência pedagógica do professor universitário. 2 ed. ver. - São Paulo: Summus, 2012.

MOURA, Maria Cecília de. Surdez e linguagem. IN: LACERDA, Cristina Broglia Feitosa de; SANTOS, Lara Ferreira Santos. (Orgs). Tenho um aluno surdo, e agora. Introdução à Libras e educação de surdos. São Carlos: EdUFSCar, 2014.

QUADROS. Ronice Muller de; KARNOPP. L. B. Língua de sinais brasileira: estudos linguísticos - Porto Alegre: Artmed, 2004.

SILVA, Tomaz Tadeu da. Documentos de identidade: uma introdução às teorias do currículo. 3. Ed. Belo Horizonte: Autêntica, 2009.

TARDIF, Maurice. Saberes docentes e formação profissional. Tradução de Francisco Pereira. Petrópolis: Vozes, 2012.

VELOSO, Éden; MAIA FILHO, Valdeci. Aprenda Libras com eficiência e rapidez. Vol. 1. Curitiba, PR: Mãos e Sinais, 2009.

Francisca Melo Agapito - Pedagoga. Especialista em Metodologia do Ensino Superior e Libras. Mestra em Ensino pelo Centro Universitário UNIVATES. Professora da Universidade Federal do Maranhão - UFMA. Email: franciscaagapito@gmail.com 


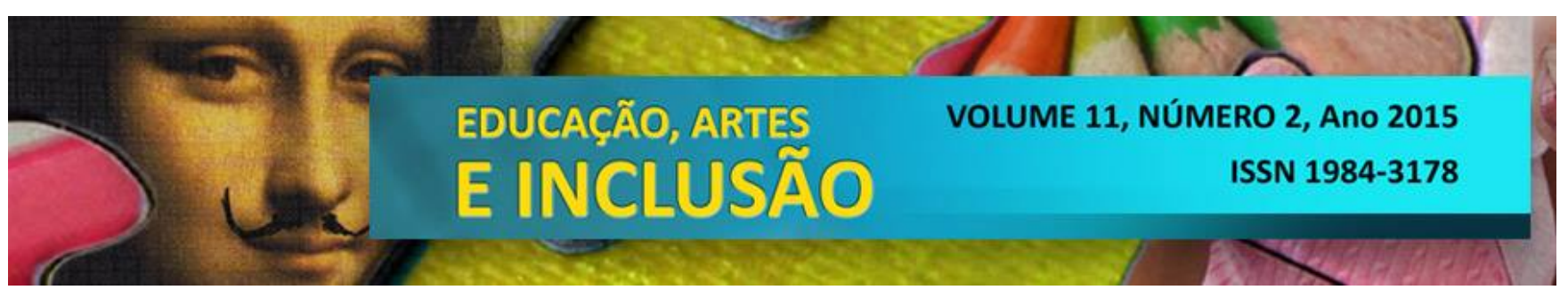

Andreia Aparecida Guimarães Strohschoen - Doutora em Ciências, ênfase em Ecologia pela UFRGS. Docente do Mestrado Profissional em Ensino de Ciências Exatas e Mestrado em Ensino da UNIVATES. Email: aaguim@univates.br

Maria Isabel Lopes - Doutora em Educação. Professora adjunta do Centro Universitário UNIVATES. Coordenadora Pedagógica do Curso de Medicina da UNIVATES. Email: milopes@univates.br

Marcelo Franco Leão Marcelo Franco Leão - Mestre em Ensino pela UNIVATES. Doutorando pela UFRG. Professor da Universidade do Estado de Mato Grosso (UNEMAT). Professor do Instituto Federal de Mato Grosso (IFMT) - Campus Confresa. Tutor do Curso de Licenciatura em Química do Instituto Federal de Mato Grosso (IFMT/UAB). Email: marcelofrancoleao@yahoo.com.br 